\title{
Glycosyltransferases: An Efficient Tool for the Enzymatic Synthesis of Oligosaccharides and Derivatives as well as Mimetics Thereof
}

\author{
Said Rabbani, Oliver Schwardt, and Beat Ernst*
}

\begin{abstract}
Research over the past two decades has uncovered numerous biological roles for carbohydrates, e.g. in cell adhesion processes, signal transduction, malignant transformation, or viral and bacterial cell-surface recognition. Carbohydrates and structural analogues thereof are therefore considered as potential new leads. Although the chemical synthesis of carbohydrates is well established, the preparation of particular oligosaccharides still remains a costly and cumbersome challenge. A complementary approach to the chemical synthesis is the use of enzymatic methods. The transfer of monosaccharide moieties to natural substrates, catalyzed by glycosyltransferases, exhibits excellent chemo-, regio- and stereoselectivity. In addition, enzymatic glycosylations permit the synthesis of carbohydrate derivatives and even carbohydrate mimetics. Our results reveal a remarkable synthetic potential of fucosyltransferases VI (EC 2.4.1.65) and III (EC 2.4.1.65), and $\alpha(2 \rightarrow 3)$-sialyltransferase ST3Gal III (EC 2.4.99.6). Their use for the preparative synthesis of oligosaccharides and derivatives as well as mimetics thereof is demonstrated.
\end{abstract}

Keywords: Enzymatic synthesis · Gangliosides · Glycosyltransferases · Myelin-associated glycoprotein · Selectins · Sialyl Lewis ${ }^{x / a}$

\section{Introduction}

Research over the past two decades has uncovered numerous biological roles for carbohydrates, ranging from functions as simple as energy storage, to complex processes that regulate transport, protein function, intercellular adhesion, signal transduction, malignant transformation, or viral and bacterial cell-surface recognition [1]. As more and more carbohydrate-related drug targets are discovered and validated, the tremendous pharmaceutical potential of carbohydrates is just beginning to be exploited by the pharmaceutical industry.

${ }^{\star}$ Correspondence: Prof. Dr. B. Ernst Institute of Molecular Pharmacy

Department of Pharmaceutical Sciences

University of Basel

Pharmacenter

Klingelbergstrasse 50

$\mathrm{CH}-4056$ Basel

Tel.: + 41612671551

Fax +41612671552

E-Mail: beat.ernst@unibas.ch

www.pharma.unibas.ch/molpharm/
The corresponding carbohydrate ligands, and especially structural analogues thereof, with improved pharmacokinetic properties are therefore considered as potential new leads. Thus, considerable research efforts devoted to (i) selectin antagonists as potential anti-inflammatory therapeutics [2], (ii) neuraminic acid derivatives as inhibitors of the adhesion of influenza viruses to their host cells [2][3], (iii) immunological aspects of the $\alpha$-Gal-epitope in xenotransplantation [4], and (iv) the role of carbohydrate antagonists of the myelin-associated glycoprotein in nerve regeneration [5].

In order to further elucidate the pharmaceutical potential of oligosaccharides and glycoconjugates, and to provide carbohydrate lead structures to medicinal chemists enabling them to develop novel carbohydrate-based therapeutics, libraries of diverse natural and modified oligosaccharides have to be synthesized and screened. Although the chemical synthesis of glycosides is well established [6], some drawbacks still exist. Owing to (i) insufficient diastereoselectivity of glycosylation reactions, particularly in the case of chemical sialylation and fucosylation, and (ii) regiochemical challenges requiring time-consuming protection and deprotection steps, oligosaccharide synthesis is still a difficult and cumbersome synthetic area. The recent development of solid phase oligosaccharide synthesis by Seeberger et al. [7] dramatically improved the efficiency of oligosaccharide synthesis, various regio- and stereochemical aspects, however, remain unsolved.

With a pioneering approach for the establishment of glycosidic linkages, namely the application of isolated or over-expressed glycosyltransferases (GTs), the groups of Paulson [8], Wong [9] and Augé [10] made complex oligosaccharides synthetically available. GTs such as galactosyl-, fucosyl- and sialyltransferases, are type II transmembrane glycoproteins located inside the Golgi apparatus [11]. They consist of a short $\mathrm{N}$-terminal cytoplasmic domain, a transmembrane domain with a 'stem' region easily cleavable by proteases, and a large C-terminal catalytic domain. Soluble forms have also been found, e.g. in human milk [12]. The biosynthesis of oligosaccharides involves the sequential action of GTs (EC 2.4.x.y), which transfer activated sugar nucleotides specifically to acceptor substrates, forming glycosidic bonds regio- and stereoselectively. Gener- 
ally, glycosyltransfers proceed by inversion at the anomeric centre of the corresponding sugar nucleotide, however, for some glycosyltransferases, e.g. bovine $\alpha(1 \rightarrow 3)$-galactosyltransferase (EC 2.4.1.90) [4c], retention of stereochemistry at the $\mathrm{C}-1$ position of the donor sugar is reported [13]. Up to now, more than 12,000 sequences encoding GTs in different organisms have become available in a glycosyltransferase database, and classified into 77 families [14]. A multitude of eukaryotic genes coding for GTs has been cloned, and their corresponding enzymes expressed, characterized and applied for oligosaccharide synthesis.

In this communication, we report applications of mammalian and bacterial fucosyl- and sialyltransferases for the enzymatic synthesis of oligosaccharides and derivatives thereof, which are of particular interest as myelin-associated glycoprotein blockers [5] or selectin antagonists [2].

\section{Chemo-enzymatic Synthesis of Myelin-associated Glycoprotein (MAG) Antagonists}

The adult mammalian central nervous system (CNS) has - unlike the peripheral nervous system (PNS) - no capacity for regeneration [15]. Originally, it was believed that this lack of regeneration is inherent to the CNS. However, it is now known that neurite outgrowth is principally possible [16], but is actively inhibited by inhibitor proteins expressed by myelinating glia cells, oligodendrocytes, and Schwann cells [17]. Three inhibitor proteins have been identified so far: Nogo-A [18], oligodendrocyte myelin glycoprotein (OMpg) [19] and myelin-associated glycoprotein (MAG) [20]. It appears that these three proteins all bind to the same receptor, Nogo-66 [21], that subsequently forms a complex with the $\mathrm{p} 75^{\mathrm{NTR}}$ co-receptor. This leads to the transduction of the inhibitory signal into the cytosol of the neuron, where it activates RhoA, which in turn causes growth cone collapse [22]. This cascade has also been shown to be triggered by MAG binding to gangliosides with p75 ${ }^{\text {NTR }}$ as co-receptor [23] (Fig. 1).

MAG has been identified as a sialic acid-binding immunoglobulin-like lectin (Siglec-4). Its role [24] as one of several myelin components inhibiting axonal regrowth after injury has attracted a lot of attention [25]. Although the mechanism is still not fully understood, it is believed that reversion of the inhibitory activity of MAG could support the regeneration of the central nervous system after injury. Schnaar and coworkers [5] reported that a limited set of structurally related gangliosides, e.g. GD1a or GT1b (Fig. 2), known to be expressed on myelinated neurons in vivo, are functional ligands of MAG. The recently

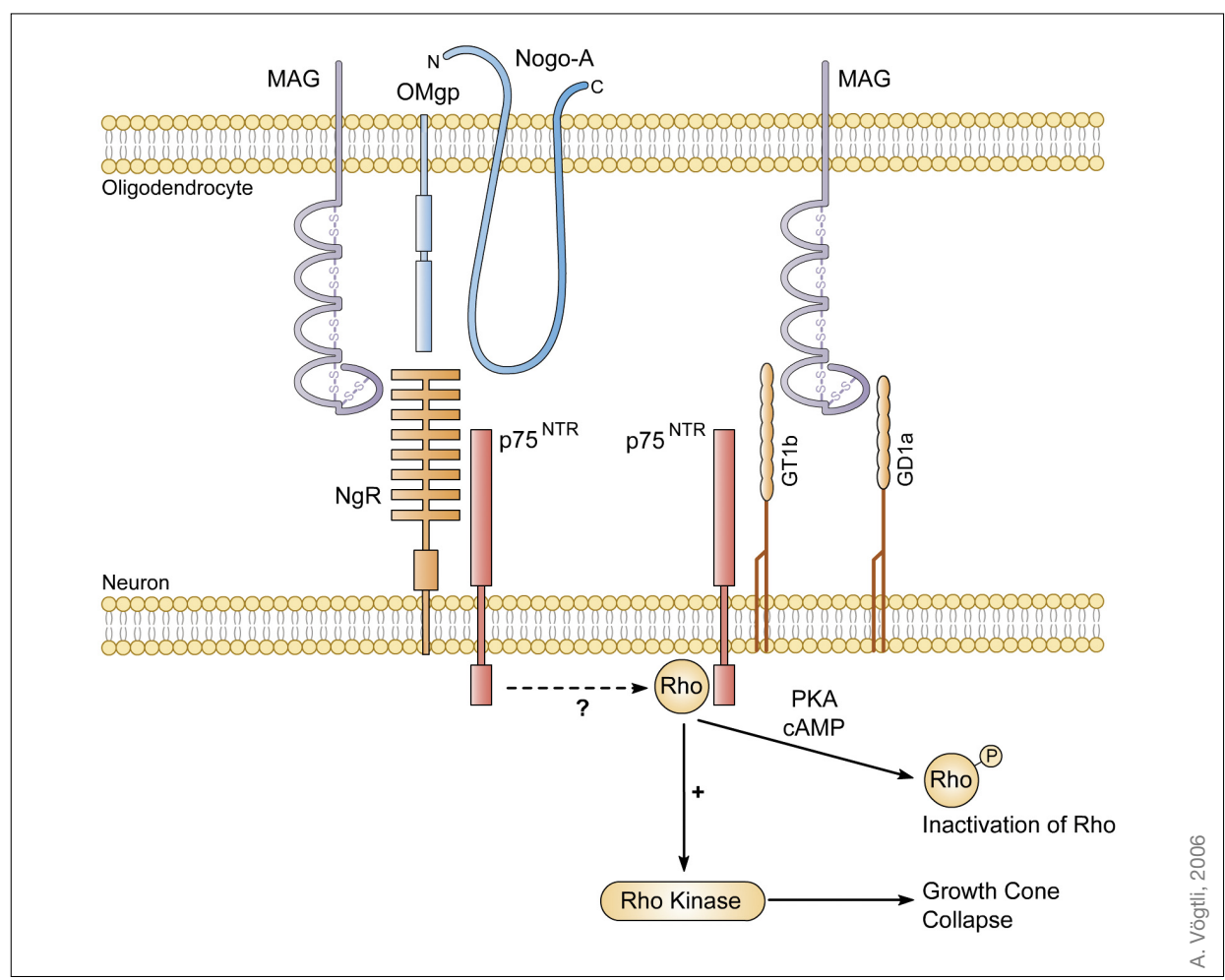

Fig. 1. MAG, Nogo 66 and oligodendrocyte myelin glycoprotein (OMgp) all bind to the Nogo-66 receptor $(\mathrm{NgR})$. The inhibitory signal is transduced into the cytosol of the neuron via the co-receptor $\mathrm{p} 75^{\mathrm{NTR}}$. MAG also binds to GT1b with $\mathrm{p} 75^{\mathrm{NTR}}$ as co-receptor, and, thereby, transduces the inhibitory signal into the cytosol. Intracellularly, the small GTPase RhoA is activated, which leads to a collapse of the growth cone.

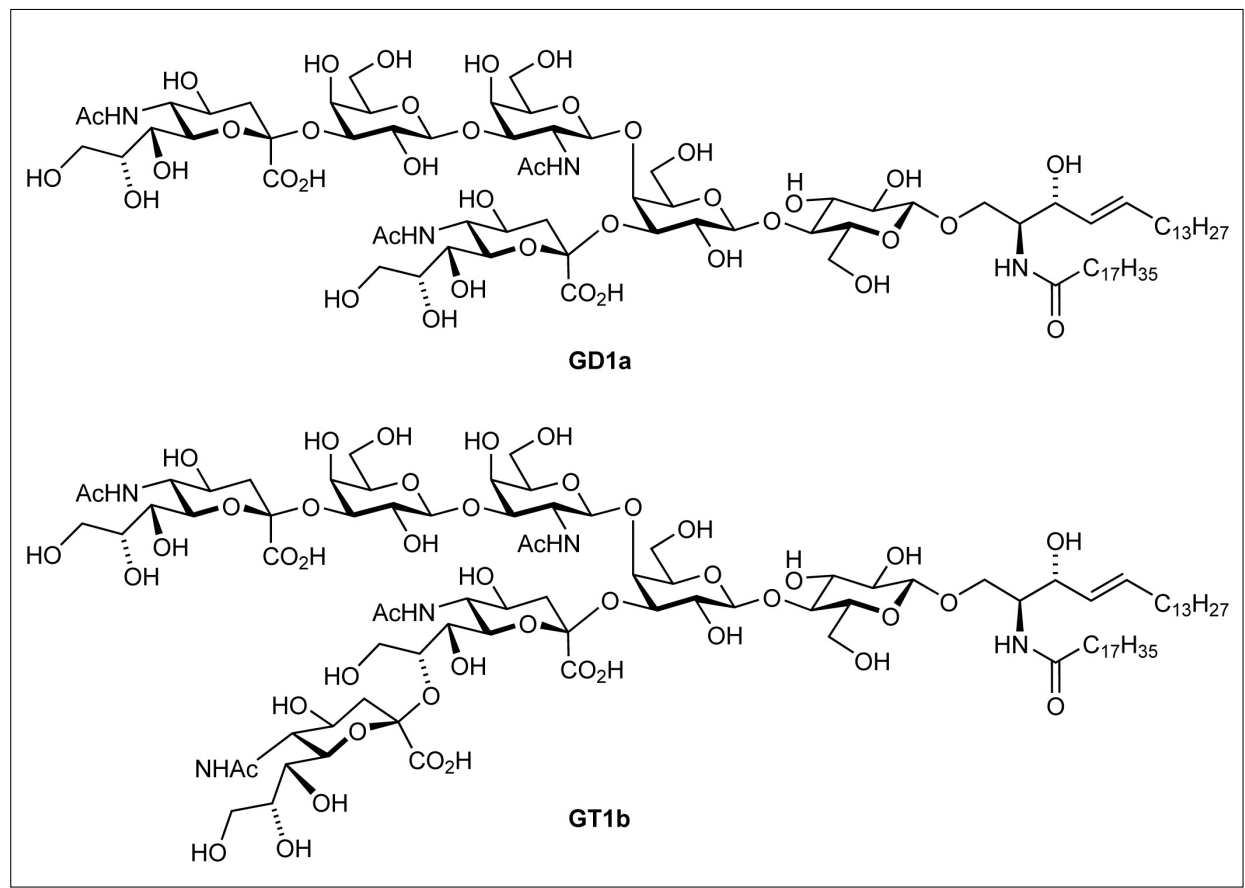

Fig. 2. The gangliosides GD1a and GT1b

reported ability to reverse MAG inhibition with monovalent glycosides [26] encourages further exploration of glycans and glycan mimics as inhibitors of MAG-mediated axonal outgrowth inhibition.

Based on structure-activity relationship (SAR) studies [27], the terminal trisaccharide of GD1a and GT1b, NeuNAco(2 $\rightarrow$
3) Gal $\beta(1 \rightarrow 3)$ GalNAc (1), was identified as the major contributor to MAG-binding [5]. It was therefore used as the starting point for a lead optimization program.

Chemical sialylation reactions still belong to the most difficult glycosylation reactions, because the hindered tertiary anomeric centre often leads to unacceptably 
low yields, and the lack of a participating group next to the anomeric centre leads to low stereoselectivity [28]. For the synthesis of sialylated trisaccharides to be tested as MAG antagonists, an alternative - enzymatic - approach using sialyltransferases was therefore explored.

The rat liver $\alpha(2 \rightarrow 3)$-sialyltransferase (rST3Gal III, EC 2.4.99.6) catalyzes $\alpha$-selectively the transfer of a sialic acid moiety from cytidine-5'-monophospho- $N$-acetylneuraminic acid (CMP-NeuNAc) onto the $3-\mathrm{OH}$ group of a terminal $\beta$-linked D-galactose (see Scheme 1). The natural substrates of $r S T 3 G a l$ III are type I [Gal $\beta(1 \rightarrow 3) \mathrm{GlcNAc}]$ and type II $[\mathrm{Gal} \beta(1 \rightarrow 4)$ GlcNAc] epitopes [8a,b]. Following standard sialylation protocols [29], incubation of substrates 2 (type II, entry 1) and 3 (type I, entry 2) with CMP-NeuNAc and recombinant $r S T 3$ Gal III gave the corresponding sialylated trisaccharides $\mathbf{8}$ and $\mathbf{9}$, respectively, in excellent yields (Table 1) [30].

However, since the desired trisaccharide lead 1 contains a type III core $[\mathrm{Gal} \beta(1 \rightarrow$ 3)GalNAc], the substrate tolerance of the rat ST was further explored. It was thus found that the type III disaccharides 4-6 were also well tolerated by $\mathrm{rST} 3 \mathrm{Gal}$ III furnishing MAG antagonists 1, 10, and 11 in acceptable yields (entries 3-5). The 6-Osialylated trisaccharide 7 , however, was not accepted by the enzyme, probably due to the bulkiness of the polar substituent at the 6-position of galactose.

\section{Chemo-enzymatic Synthesis of Sialyl Lewis ${ }^{x}\left(\right.$ se $\left.^{x}\right)$ Derivatives}

Leukocyte recruitment to sites of injury or infection is an important defence mechanism of the immune system. However, the excessive infiltration of inflamed tissues by leukocytes can cause acute or chronic conditions such as reperfusion injury, stroke, psoriasis, rheumatoid arthritis, and respiratory diseases [31]. Consequently, there is a great medical need for the prevention of excessive leukocyte recruitment, which takes place in a regulated chain of events: rolling, firm adhesion, and transendothelial migration (Fig. 3). The first step in the inflammatory cascade - leukocyte rolling - is mediated largely by a family of cell adhesion molecules, E-, P- and L-selectins and their carbohydrate ligands [32].

The tetrasaccharide sialyl Lewis ${ }^{\mathrm{x}}\left(\mathrm{sLe}^{\mathrm{x}}\right)$ has been identified as the carbohydrate epitope mediating leukocyte rolling on endothelial cells and thereby initiating the inflammatory response [33]. $\alpha(1 \rightarrow 3)$-Fucosyltransferase VI (FucT VI, EC 2.4.1.65) catalyzes the last step in $\mathrm{sLe}^{\mathrm{X}}$ biosynthesis. The enzyme transfers L-fucose from GDPfucose onto the 3-OH group of galactose of the type II, or sialylated type II, epitope to form $\alpha(1 \rightarrow 3)$-glycosidic linkages of Lewis ${ }^{\mathrm{x}}$

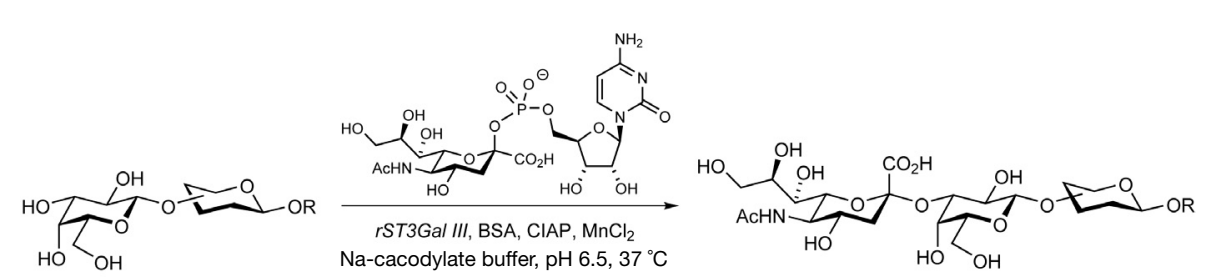

Scheme 1. Enzymatic sialylations of type I [Gal $\beta(1 \rightarrow 3) \mathrm{GlcNAc}$, type II [Gal $\beta(1 \rightarrow 4) \mathrm{GlcNAc}]$ and type III [Gal $\beta(1 \rightarrow 3)$ GalNAc] saccharides using rST3Gal III and CMP-NeuNAc

Table 1. Isolated yields of enzymatic sialylations of type I, II, and III saccharides ${ }^{\mathrm{a}}$

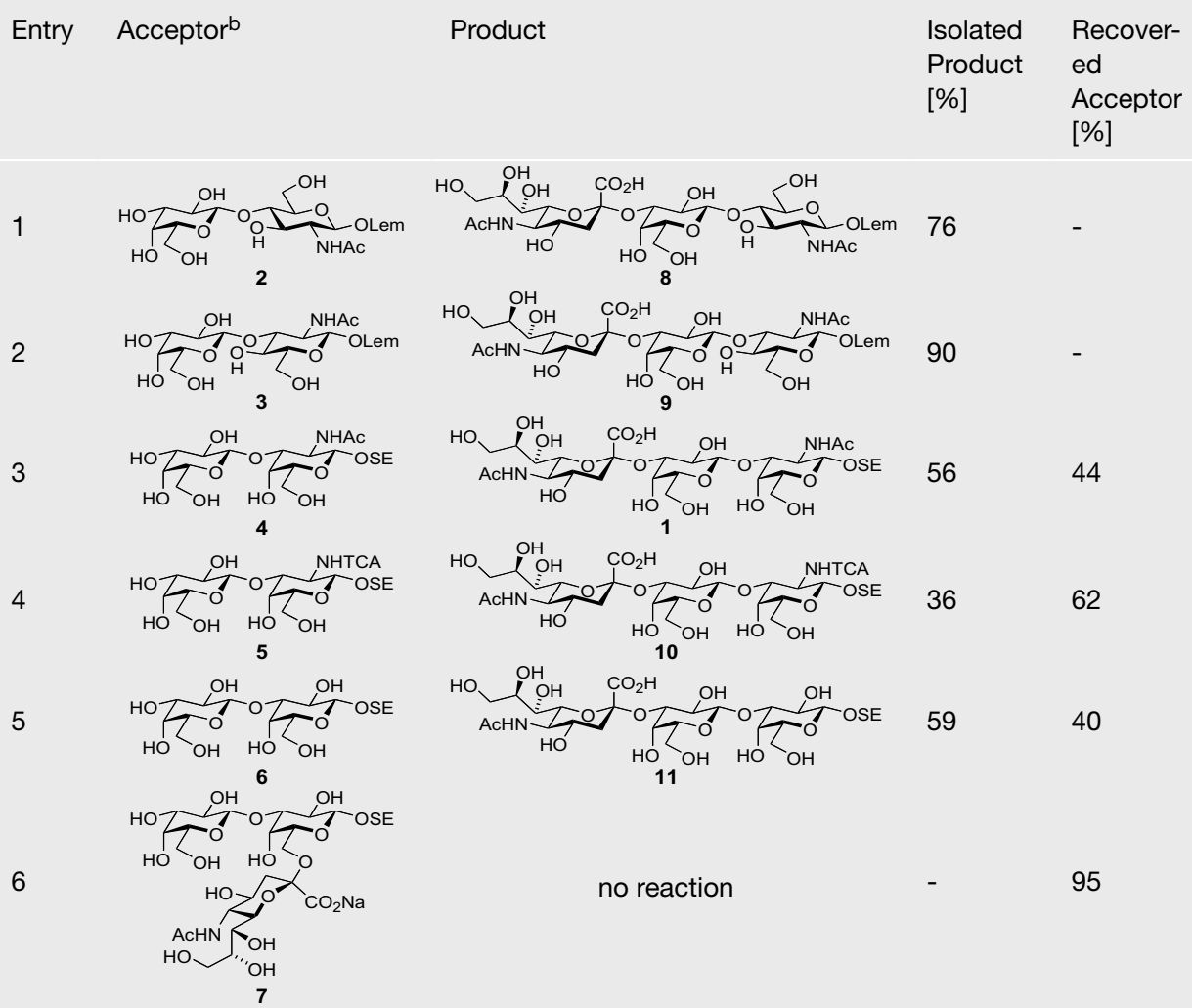

a Substrates and CMP-NeuNAc were incubated with $r S T 3 G a l ~ I I I$ for $3-5 \mathrm{~d}$ at $37^{\circ} \mathrm{C}$ in a mixture of $50 \mathrm{mM}$ sodium cacodylate buffer $\left(\mathrm{pH} \mathrm{6.5)}\right.$ and $60 \mathrm{mM} \mathrm{MnCl}_{2}$-solution containing BSA and CIAP (EC 3.1.3.1).

b 2, 3: 3 mg; 4-7: 10 mg scale.

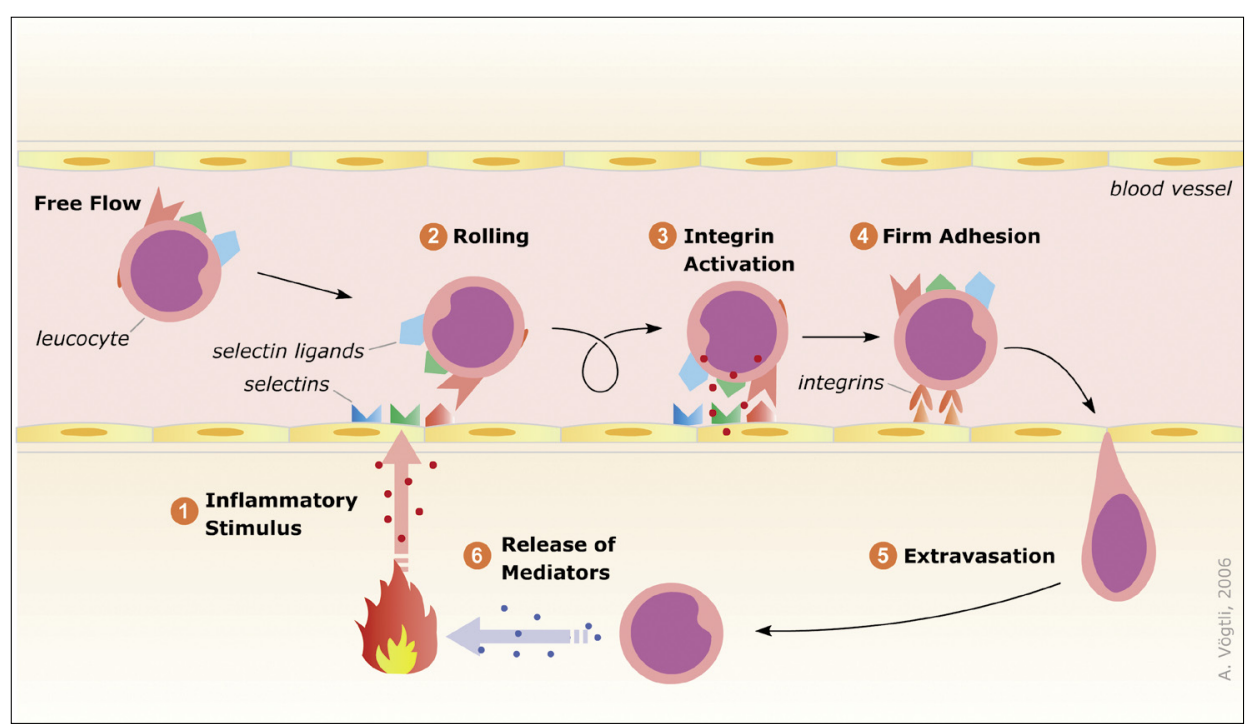

Fig. 3. The inflammatory cascade 
trisaccharides or sialyl Lewis ${ }^{\mathrm{x}}$ tetrasaccharides, respectively [34]. In a study aimed at exploring the protein surface next to the nitrogen of the glucosamine in sLe ${ }^{\mathrm{x}}$, a library of modified sLe ${ }^{\mathrm{x}}$-tetrasaccharides 14 was enzymatically synthesized on a preparative scale and in good overall yields [35]. For this, a series of lactosamine derivatives $\mathbf{1 2}$ was first sialylated using $\mathrm{rST} 3 \mathrm{Gal} \mathrm{III}$, and the resulting trisaccharides 13 were subsequently fucosylated with FucT VI (Scheme 2).

The replacement of the $N$-acetyl group by aromatic or heteroaromatic moieties (entries 3 and 7 in Table 2), charged residues (entries 4 and 5) or sulfonamides (entry 6) is well tolerated by both transferases. Bulky polar saccharopeptides (entry 8) are also easily glycosylated in the expected manner. Surprisingly, the natural $N$-acetyl group of the glucosamine unit is not a key recognition element for $F u c T V I$, although fucosylation takes place at the hydroxyl group adjacent to the $\mathrm{N}$-acyl group.

Prokaryotic glycosyltransferases that accomplish transformations analogous to mammalian enzymes are of great interest because they can be produced in simple and cost effective bacterial expression systems. The synthetic potential of a cloned $H$. pylori $\alpha(1 \rightarrow 4)$-FucT [36] was evaluated for the synthesis of $\mathrm{sLe}^{\mathrm{a} / \mathrm{x}}$ derivatives containing replacements of the GlcNAc and/or NeuNAc moieties by non-carbohydrate structures (Scheme 3).

The pseudotriaccharide 15 (entry 2 in Table 3), in which GlcNAc is substituted by $(R, R)$-cyclohexan-1,2-diol and NeuNAc by $(R)$-cyclohexyllactic acid, was tolerated as a substrate, although with a reduced activity $(3.8 \%)$ compared to the natural substrate. The $(S)$-lactic acid derivative $\mathbf{1 6}$ (entry 3 ) proved to be an excellent substrate (100\%)

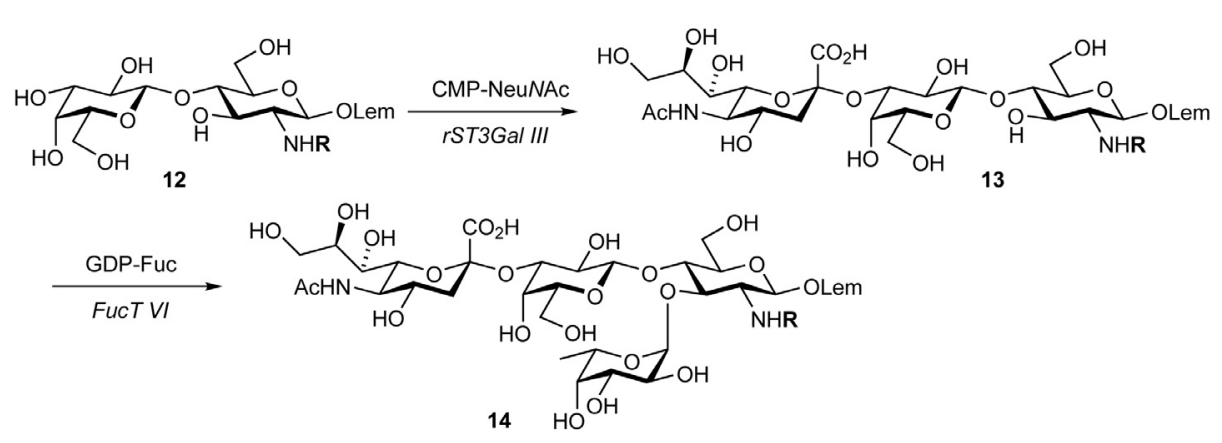

Scheme 2. Synthesis of $\mathrm{SLe}^{\mathrm{x}}$-derivatives via enzymatic sialylation and fucosylation of non-natural type II saccharides

Table 2. Isolated yields of enzymatic sialylations ${ }^{a}$ and fucosylations ${ }^{b}$ of non-natural type II saccharides 12

\begin{tabular}{|c|c|c|c|c|c|c|c|}
\hline Entry & $\begin{array}{l}\mathrm{R} \text { (acyl } \\
\text { group) }\end{array}$ & $\begin{array}{l}\text { Yield of } \\
\text { sialylation } \\
\text { [\%] }\end{array}$ & $\begin{array}{l}\text { Yield of } \\
\text { fucosyla- } \\
\text { tion } \\
\text { [\%] }\end{array}$ & Entry & $\begin{array}{l}\mathrm{R} \text { (acyl } \\
\text { group) }\end{array}$ & $\begin{array}{l}\text { Yield of } \\
\text { sialylation } \\
\text { [\%] }\end{array}$ & $\begin{array}{l}\text { Yield of } \\
\text { fuco- } \\
\text { sylation } \\
\text { [\%] }\end{array}$ \\
\hline 1 & & 76 & 82 & 5 & & 92 & 45 \\
\hline 2 & & 72 & 88 & 6 & & 92 & 91 \\
\hline 3 & & 81 & 89 & 7 & & 74 & 64 \\
\hline 4 & & 49 & 64 & 8 & & 95 & 60 \\
\hline
\end{tabular}

a Substrates and CMP-NeuNAc were incubated with $r S T 3 G a l ~ I I I$ for $1-2 \mathrm{~d}$ at $37^{\circ} \mathrm{C}$ in a mixture of $50 \mathrm{mM}$ sodium cacodylate buffer $(\mathrm{pH} 6.5)$ and $60 \mathrm{mM} \mathrm{MnCl}_{2}$-solution containing BSA and CIAP (EC 3.1.3.1).

b Substrates and GDP-Fuc were incubated with FucT VI for $1-3 \mathrm{~d}$ at $37{ }^{\circ} \mathrm{C}$ in a mixture of $250 \mathrm{mM}$ sodium cacodylate buffer ( $\mathrm{pH} 6.5)$ and $250 \mathrm{mM} \mathrm{MnCl}_{2}$-solution containing BSA and CIAP. when exposed to the enzymatic fucosylation. However, the activity was practically abolished when compound $\mathbf{1 8}$ (entry 5, GlcNAc replaced by $(R, R)$-butan-2,3-diol and Neu$N A c$ by $(S)$-3-phenyllactic acid) was used as substrate. Finally, reduced activity was also observed with substrates 17 (6.5\%, entry 4) and $19(2.1 \%$, entry 6). Although in some cases the reaction rates are low compared to the natural epitope (entry 1), they are still sufficient for preparative enzymatic syntheses.

\section{Conclusions and Perspectives}

Glycosyltransferases assemble natural oligosaccharides with excellent regio- and stereoselectivity. However, for the synthesis of libraries of oligosaccharides and derivatives thereof, a broader substrate tolerance would be preferable. To explore the synthetic potential of some selected bacterial and mammalian glycosyltransferases (ST3Gal III, FucT III and FucT VI) a broad range of unnatural substrates was tested. Interestingly, most of these substrates were accepted, although some of them showed only distinctively reduced reaction rates. However, these do not make preparative applications impossible.

For a further expansion of the substrate tolerance as well as the resistance to organic solvents, detergents or elevated temperature, GTs may be modified by random or directed mutations. Theses new enzymes will further expand the synthetic range of enzymatic glycosylations, and therefore, facilitate the synthesis of libraries of oligosaccharide derivatives and mimetics thereof.

Received: January 23, 2006

[1] a) R.S. Haltiwanger, J.B. Lowe, Annu. Rev. Biochem. 2004, 73, 491-537; b) J. Alper, Science 2001, 291, 2338-2343; c) J.C. McAuliffe, O. Hindsgaul, Chem. Ind. 1997, 170-174; d) Y. Nagai, Pure Appl. Chem. 1997, 69, 1893-1896; e) R.A. Dwek, Chem. Rev. 1996, 96, 683-720; f) P.M. Simon, Drug Discovery Today 1996, $1,522-528$.

[2] B. Ernst, H.C. Kolb, O. Schwardt, in 'The Organic Chemistry of Sugars', Eds. D.E. Levy, P. Fügedi, CRC Press, Boca Raton, London, New York, 2006, pp. 803-861.

[3] M. Matrosovich, H.D. Klenk, Rev. Med. Virol. 2003, 13, 85-97.

[4] a) K. Kuwaki, C. Knosalla, K. Moran, A. Alt, A.G. Katopodis, R.O. Duthaler, H.J. Schuurman, M. Awwad, D.K. Cooper, Xenotransplantation 2004, 11, 210-215; b) A.G. Katopodis, R.G. Warner, R.O. Duthaler, M.B. Streiff, A. Bruelisauer, O. Kretz, B. Dorobek, E. Persohn, H. Andres, A. Schweitzer, G. Thoma, W. Kinzy, V.F.J. Quesniaux, E. Cozzi, H.F.S. Davies, R. Mañez, D. White, J. Clin. Invest. 2002, 110, 


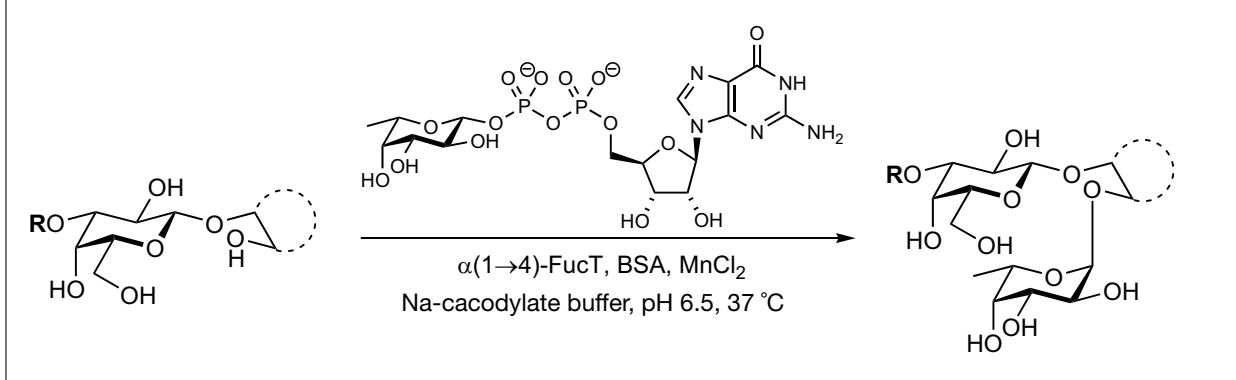

Scheme 3. Enzymatic fucosylations of non-natural substrates using $H$. pylori $\alpha(1 \rightarrow 4)$-FucT and GDP-Fuc

Table 3. Enzymatic fucosylations ${ }^{\mathrm{a}}$ of non-natural substrates

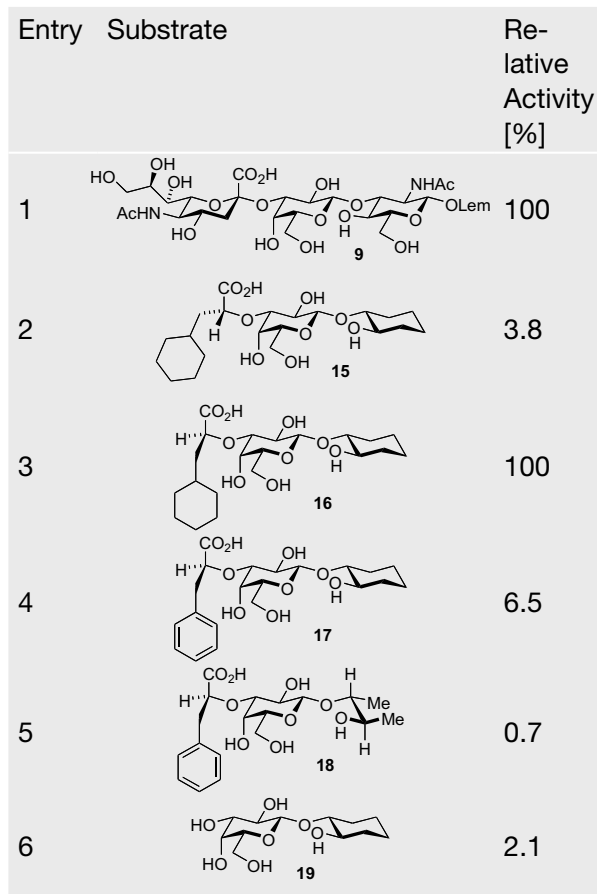

a Substrates and GDP-[ $\left[{ }^{14} \mathrm{C}\right]$-fucose were incubated with $H$. pylori $\alpha(1 \rightarrow 4)$-FucT for 30 min at $37^{\circ} \mathrm{C}$ in a mixture of $50 \mathrm{mM}$ sodium cacodylate buffer ( $\mathrm{pH} 6.5)$ and $20 \mathrm{mM} \mathrm{MnCl}_{2}$ solution containing BSA. The enzymatic activity was quantified as the amount of radioactivity transferred from $\mathrm{GDP}-\left[{ }^{14} \mathrm{C}\right]-$ fucose to the corresponding acceptor (in \% relative to 9 ).

1869-1877; c) O. Schwardt, G. Baisch, R. Öhrlein, Bioorg. Med. Chem. 2001, 9, 1857-1869.

[5] a) L.S. Yang, C.B. Zeller, N.L. Shaper, M. Kiso, A. Hasegawa, R.E. Shapiro, R.L. Schnaar, PNAS 1996, 93, 814-818; b) A.A. Vyas, H.V. Patel, S.E. Fromholt, M. HefferLauc, K.A. Vyas, J. Dang, M. Schachner, R.L. Schnaar, PNAS 2002, 99, 8412-8417.

[6] 'Carbohydrates in Chemistry and Biology', Eds. B. Ernst, G.W. Hart, P. Sinaÿ, WileyVCH, Weinheim, 2000, Vol. 1 \& 2.

[7] a) P.H. Seeberger, D.B. Werz, Nat. Rev. Drug Discovery 2005, 4, 751-763; b) O.J. Plante, E.R. Palmacci, P.H. Seeberger, Meth. Enzymol. 2003, 369, 235-248.
[8] a) M.A. Williams, H. Kitagawa, A.K. Datta, J.C. Paulson, J. Jamieson, Glycoconjugate J. 1995, 12, 755-761; b) D.X. Wen, B.D. Livingstone, K.F. Medzihradszky, S. Kelm, A.L. Burlingame, J.C. Paulson, J. Biol. Chem. 1992, 267, 21011-21019; c) J.E. Sadler, T.A. Beyer, C.L. Oppenheimer, J.C. Paulson, J.P. Prieels, J.I. Rearick, R.L. Hill, Meth. Enzymol. 1982, 83, 458-514.

[9] C.H. Wong, S.L. Haynie, G.M. Whitesides, J. Org. Chem. 1982, 47, 5416-5418.

[10] C. Augé, C. Mathieu, C. Merienne, Carbohydr. Res. 1986, 151, 147-156.

[11] J.C. Paulson, K.J. Colley, J. Biol. Chem. 1989, 264, 17615-17618.

[12] J.P Prieels, D. Monnom, M. Dolmans, T.A. Beyer, R.L. Hill, J. Biol. Chem. 1981, 256, 10456-10463.

[13] M.L. Sinnott, Chem. Rev. 1990, 90, 11711202.

[14] P.M. Coutinho, B. Henrissat, Carbohydrate-active Enzymes Server, 1999, http:// afmb. cnrs-mrs.fr/CAZY/

[15] M.E. Schwab, J.P. Kapfhammer, C.E. Bandtlow, Annu. Rev. Neurosci. 1993, 16, 565-595.

[16] S.J. Davies, D.R. Goucher, C. Doller, J. Silver, J. Neurosci. 1999, 19, 5810-5822.

[17] a) M.E. Schwab, P. Caroni, J. Neurosci. 1988, 8, 2381-2393; b) P. Caroni, T. Savio, M.E. Schwab, Prog. Brain Res. 1988, 78, 363-370

[18] a) M.S. Chen, A.B. Huber, M.E. van der Haar, M. Frank, L. Schnell, A.A. Spillmann, F. Christ, M.E. Schwab, Nature 2000, 403, 434-439; b) T. GrandPré, F. Nakamura, T. Vartanian, S.M. Strittmatter, Nature 2000, 403, 439-444.

[19] a) V. Kottis, P. Thibault, D. Mikol, Z.C. Xiao, R. Zhang, P. Dergham, P.E. Braun, $J$. Neurochem. 2002, 82, 1566-1569; b) K.C. Wang, V. Koprivica, J.A. Kim, R. Sivasankaran, Y. Guo, R.L. Neve, Z. He, Nature 2002, 417, 941-944.

[20] a) L. McKerracher, S. David, D.L. Jackson, V. Kottis, R.J. Dunn, P.E. Braun, Neuron 1994, 13, 805-811; b) G. Mukhopadhyay, P. Doherty, F.S. Walsh, P.R. Crocker, M.T. Filbin, Neuron 1994, 13, 757-767; c) M. Vinson, P.J.L.M. Strijbos, A. Rowles, L. Facci, S.E. Moore, D.L. Simmons, F.S. Walsh, J. Biol. Chem. 2001, 276, 2028020285.

[21] A.E. Fournier, T. GrandPre, S.M. Strittmatter, Nature 2001, 409, 341-346.
[22] G. Yiu, Z. He, Curr. Opin. Neurobiol. 2003, 13, 133-139.

[23] T. Yamashita, H. Higuchi, M. Tohyama, $J$. Cell. Biol. 2002, 157, 565-570.

[24] a) S. Kelm, A. Pelz, R. Schauer, M.T. Filbin, S. Tang, M.E. de Bellard, R.L. Schnaar, J.A. Mahoney, A. Hartnell, P. Bradfield, P.R. Crocker, Curr. Biol. 1994, 4, 965-972; b) P.R. Crocker, E.A. Clark, M.T. Filbin, S. Gordon, Y. Jones, J.H. Kehrl, S. Kelm, N.M. Le Douarin, L. Powell, J. Roder, R.L. Schnaar, D. Sgroi, I. Stamenkovic, R. Schauer, M. Schachner, T. Tedder, T.K. van den Berg, P.A. van der Merwe, S.M. Watt, A. Varki, Glycobiology 1998, 8, Glycoforum $2 \mathrm{v}$-vi.

[25] L. McKerracher, PNAS 2002, 99, 78117813.

[26] A.A. Vyas, O. Blixt, J.C. Paulson, R.L. Schnaar, J. Biol. Chem. 2005, 280, 1630516310.

[27] O. Schwardt, G.-P. Gao, S. Shelke, B. Ernst, unpublished results.

[28] G.-J. Boons, A.-V. Demochemko, Chem. Rev. 2000, 100, 4539-4565.

[29] a) B. Ernst, B. Wagner, G. Baisch, A. Katopodis, T. Winkler, R. Öhrlein, Can. J. Chem. 2000, 78, 892-904; b) M.M. Palcic, Meth. Enzymol. 1994, 230, 300-316.

[30] O. Schwardt, G.P. Gao, T. Visekruna, S. Rabbani, E. Gassmann, B. Ernst, J. Carbohydr. Chem. 2004, 23, 1-26.

[31] a) S.A. Mousa, Drugs Fut. 1996, 21, 283 289; b) S.A. Mousa, D.A. Cheresh, Drug Discovery Today 1997, 2, 187-199; c) D.B. Cines, E.S. Pollak, C.A. Buck, J. Loscalzo, G.A. Zimmermann, R.P. McEver, J.S. Pober, T.M. Wick, B.A. Konkle, B.S. Schwartz, E.S. Barnathan, K.R. McCrae, B.A. Hug, A.-M. Schmidt, D.M. Stern, Blood 1998, 91, 3527-3561.

[32] a) R.R. Lobb, in 'Adhesion. Its Role in Inflammatory Disease', Eds. J.M. Harlan, D.Y. Liu, W.H. Freeman, New York, 1992 p. 1; b) J.C. Paulson, in 'Adhesion. Its Role in Inflammatory Disease', Eds. J.M. Harlan, D.Y. Liu, W.H. Freeman, New York, 1992, p. 19; c) G.S. Kansas, Blood 1996, 88, 3259-3287; d) A. Varki, PNAS 1994, 91, 7390-7397.

[33] a) A.J. Schottelius, A. Hamann, K. Asadullah, Trends Immunol. 2003, 24, 101-104; b) R. Kannagi, Curr. Opin. Struc. Biol. 2002, 12, 599-608.

[34] K.L. Koszdin, B.R. Bowen, Biochem. Biophys. Res. Commun. 1992, 187, 152-157.

[35] a) B. Ernst, Z. Dragic, S. Marti, C. Müller, B. Wagner, W. Jahnke, J.L. Magnani, K.E. Norman, R. Öhrlein, T. Peters, H.C. Kolb, Chimia 2001, 55, 268-274; b) R. Öhrlein, Topics Curr. Chem. 1999, 200, 227-254; c) B. Ernst, R. Öhrlein, Glycoconjugate J. 1999, 16, 161-170.

[36] S. Rabbani, V. Miksa, B. Wipf, B. Ernst, Glycobiology 2005, 15, 1076-1083. 